
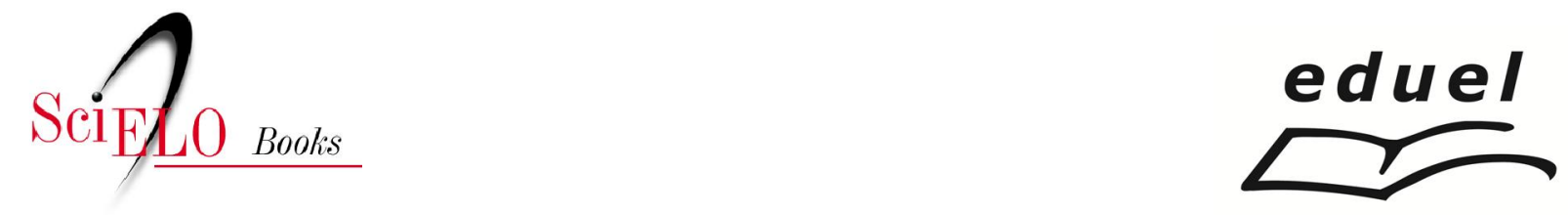

\title{
Abordagem intensiva
}

\author{
Sandra Odebrecht Vargas Nunes \\ Heber Odebrecht Vargas \\ Márcia Regina Pizzo de Castro \\ Regina Célia Bueno Rezende Machado \\ David Roberto do Carmo
}

NUNES, SOV., et al. Abordagem intensiva. In NUNES, SOV., and CASTRO, MRP., orgs.

Tabagismo: Abordagem, prevenção e tratamento [online]. Londrina: EDUEL, 2011.pp. 97-116. ISBN

978-85-7216-675-1. Available from SciELO Books $<\underline{\text { http://books.scielo.org }>\text {. }}$

\section{@(1) $(0)$}

All the contents of this work, except where otherwise noted, is licensed under a Creative Commons Attribution-Non Commercial-ShareAlike 3.0 Unported.

Todo o conteúdo deste trabalho, exceto quando houver ressalva, é publicado sob a licença Creative Commons Atribuição Uso Não Comercial - Partilha nos Mesmos Termos 3.0 Não adaptada.

Todo el contenido de esta obra, excepto donde se indique lo contrario, está bajo licencia de la licencia Creative Commons Reconocimento-NoComercial-CompartirIgual 3.0 Unported. 



\title{
Abordagem Intensiva
}

\author{
Sandra Odebrecht Vargas Nunes \\ Heber Odebrecht Vargas \\ Márcia Regina Pizzo de Castro \\ Regina Célia Bueno Rezende Machado \\ David Roberto do Carmo
}

\section{ABORDAGEM GERAL DE TRATAMENTO}

O tabagismo é um transtorno crônico, recorrente; a maioria dos fumantes requer cinco a sete tentativas até conseguir parar definitivamente de fumar. Os pacientes que fumam podem expressar sentimentos ou temores que servem de obstáculos para a cessação do tabagismo. As preocupações mais comuns são os medos de ganhar peso, o medo da abstinência e de fracassar. (AMERICAN PSYCHIATRIC ASSOCIATION, 2008).

Uma grande parte dos tratamentos para tabagismo emprega algum tipo de técnica cognitivo-comportamental. A terapia comportamental procura auxiliar o fumante a identificar os gatilhos relacionados ao desejo e ao ato de fumar e utiliza técnicas cognitivas e de modificação do comportamento para interromper a associação entre a situação gatilho, a fissura de fumar e o comportamento de consumo. Frequentemente, utilizam-se estratégias para lidar com estresse e afetos positivos e negativos, solução de problemas, além do manejo dos sintomas de síndrome de abstinência. Uma vez que o fumante pare de fumar, são utilizadas técnicas de prevenção de recaída. (AMERICAN PSYCHIATRIC ASSOCIATION, 1996).

A terapia intensiva deve ser utilizada quando o paciente entra na fase de ação: deve-se estimular a definição imediata da data de parada. Um plano de ação deve ser desenhado com o paciente, avaliando os motivos que o levam a fumar e traçando estratégias para que ele resista ao desejo e aprenda a viver sem o cigarro. A partir da data escolhida, o fumante deve se afastar de tudo que lembre o cigarro (não portar cigarros, cinzeiros ou isqueiros, não consumir café e álcool, por exemplo). Para combater a fissura, orientar a beber líquidos, chupar gelo, mascar algo (balas e chicletes 
dietéticos, cristais de gengibre, canela, etc.), ou seja, usar substitutos da gratificação oral. Estratégias para manter as mãos ocupadas como, por exemplo, escrever, digitar, costurar, pintar, etc., têm se revelado bastante úteis. Essas ações reduzem a busca de fontes de prazer relacionadas ao comportamento tabagístico, caracterizadas, de forma evidente, na gratificação oral. (REICHERT et al., 2008).

Os tratamentos psicossociais para o transtorno por uso de substâncias tentam combater o uso compulsivo, ocasionando mudanças de comportamento, processos de pensamento, regulação de afeto e funcionamento social dos pacientes. Entre as diversas abordagens, todas elas ocupam-se das seguintes tarefas: 1) aumentar a motivação pra cessar ou reduzir o uso de substâncias, 2) desenvolver habilidades de enfrentamento, 3) mudar as contingências de reforço, 4) promover o gerenciamento de afetos dolorosos e 5) favorecer as relações sociais e o funcionamento interpessoal. (AMERICAN PSYCHIATRIC ASSOCIATION, 2008).

\section{ABORDAGEM PSICOSSOCIAL DE TRATAMENTO PARA O TABAGISMO}

Os tratamentos psicossociais para a cessação do tabagismo podem ser realizados individualmente ou em grupo, e devem ser conduzidos por profissional treinado. O tratamento em grupo emprega essencialmente as mesmas técnicas que o individual, mas acredita-se que possa proporcionar algumas vantagens específicas, como maior suporte social e maior facilitação da discussão de situações de risco e meios de lidar com as situações de risco. (PRESMAN; CARNEIRO; GIGLIOTTI, 2005).

As terapias cognitivo-comportamentais para a dependência do tabaco têm como base a identificação e a modificação dos padrões disfuncionais de pensamentos. As estratégias cognitivas incluem reforçar a determinação do paciente de cessar o consumo de tabaco pela exploração das consequências positivas e negativas do uso continuado, reconhecer as situações de alto risco condicionadas com o tabagismo, identificar e confrontar pensamentos disfuncionais, desenvolver estratégias para lidar com a fissura e preparar-se para recaídas. (AMERICAN PSYCHIATRIC ASSOCIATION, 2008). 
Cerca de $80 \%$ dos fumantes querem parar de fumar. No entanto, apenas $3 \%$ conseguem, a cada ano, e a maioria desse grupo para sem ajuda. A abordagem e o tratamento do fumante chegam a aumentar as taxas de cessação de $3 \%$ para $20 \%$ a $30 \%$, em um ano. É necessário o apoio formal de profissionais de saúde para obterem êxito no processo de cessação do tabagismo. (BRASIL, 2001).

\section{ABORDAGEM INTENSIVA}

A abordagem intensiva/específica consiste na estruturação de um ambulatório específico para o atendimento de fumantes que desejam parar de fumar. Pode ser feita individualmente ou em grupo de apoio. O Conselho Nacional Sobre Abordagem e Tratamento do Fumante recomenda que essa abordagem seja realizada em quatro sessões semanais, estruturadas em noventa minutos, seguidas de duas sessões semanais de sessenta minutos e uma sessão mensal de acompanhamento até completar um ano, com o objetivo de prevenir a recaída. Caso o tratamento seja realizado em grupo, em até duas sessões quinzenais, o grupo deve conter entre 10 e 15 participantes e ser fechado. As sessões mensais de acompanhamento devem ser em grupo aberto, reunindo participantes de todos os grupos anteriores. (MEIRELLES; CAVALCANTE, 2006).

Os métodos baseados na terapia comportamental cognitiva (TCC) são fundamentais na abordagem do fumante em todas as situações clínicas, mesmo quando é necessário apoio medicamentoso. $\mathrm{O}$ fumante deve se sentir bem recebido pela equipe de saúde, que deve abordá-lo com acolhimento, empatia, respeito e confiança. Não existe um "momento ideal" para deixar de fumar; mesmo diante de comorbidades graves e incapacitantes, a cessação melhora a qualidade de vida e a autoestima do fumante, muitas vezes abalada pelas doenças de base. (REICHERT et al., 2008).

A TCC deve ser oferecida tanto no atendimento individual quanto em grupo. Os atendimentos/sessões devem ser estruturados com periodicidade semanal no $1^{\circ}$ mês (parada), quinzenal até completar a abordagem intensiva (três meses) e, finalmente, mensal, até completar um ano. (REICHERT et al., 2008). 
INTERVENÇÕES DO CENTRO DE REFERÊNCIA DE ABORDAGEM E TRATAMENTO DO TABAGISMO DO AHC/UEL

O Centro de Referência de Abordagem e Tratamento do Tabagismo (CRATT), implantado no Hospital de Clínicas da Universidade Estadual de Londrina (AHC/UEL), foi credenciado pelo Ministério da Saúde, de acordo com a Portaria SAS/MS 442/04. (BRASIL, 2004a). As sessões de intervenções estão sumarizadas no quadro 9 .

\begin{tabular}{|c|c|c|}
\hline SESSÃO & DATA & ÁREA TEMÁTICA \\
\hline & & Avaliação clínica inicial \\
\hline $1^{\mathrm{a}}$ & & Entender por que se fuma e como isso afeta a saúde \\
\hline $2^{\mathrm{a}}$ & & Os primeiros dias sem fumar \\
\hline $3^{\mathrm{a}}$ & & Como vencer os obstáculos para permanecer sem fumar \\
\hline $4^{\mathrm{a}}$ & & Benefícios obtidos após parar de fumar \\
\hline $5^{\mathrm{a}}$ & & Quadro de vantagens e desvantagens - Balança Decisória \\
\hline $6^{\mathrm{a}}$ & & Habilidades para lidar com situações de risco I \\
\hline $7^{\mathrm{a}}$ & & Manejo da fissura e relaxamento \\
\hline $8^{\text {a }}$ & & Modificação no estilo de vida I \\
\hline $9^{\mathrm{a}}$ & & Modificação no estilo de vida II. \\
\hline $10^{\mathrm{a}}$ & & Autoestima e assertividade I \\
\hline $11^{\mathrm{a}}$ & & Autoestima e assertividade II \\
\hline $12^{\mathrm{a}}$ & & Maneiras de lidar com a ansiedade \\
\hline $13^{\mathrm{a}}$ & & Modificação no estilo de vida III \\
\hline $14^{\mathrm{a}}$ & & $\begin{array}{l}\text { Habilidades para lidar com as situações de risco II - Alternativas } \\
\text { seguras e de risco }\end{array}$ \\
\hline $15^{\mathrm{a}}$ & & Estratégias de enfrentamento \\
\hline $16^{\mathrm{a}}$ & & Encerramento \\
\hline
\end{tabular}

Quadro 9 - Intervenções do Centro de Referência de Abordagem e Tratamento do Tabagismo do AHC/UEL de Londrina - PR (CRATT) 
A seguir serão discutidas as 16 áreas temáticas desenvolvidas no CRATT.

A abordagem e o tratamento do fumante consistem em 16 sessões de grupos terapêuticos, entre 10 a 15 participantes, de uma hora e meia. Previamente, realiza-se a consulta inicial de avaliação clínica do fumante. As sessões grupais são estruturadas, sendo quatro sessões semanais, passando a duas sessões quinzenais e uma sessão mensal para prevenção de recaída, até completar um ano.

As quatro primeiras sessões foram estruturadas e orientadas pela equipe técnica do Instituto Nacional de Câncer/Coordenação Nacional de Controle do Tabagismo e Prevenção Primária de Câncer. O Programa Deixando de Fumar sem Mistérios é destinado a ajudar os participantes a deixarem de fumar, fornecendo-lhes todas as informações e estratégias necessárias para direcionar seus próprios esforços nesse sentido. Ele consiste de uma abordagem ativa e pragmática, em que todos os pacientes são incentivados a aplicar o que aprenderam com o Programa em outros aspectos da sua vida. (BRASIL, 2004b).

Na primeira sessão do grupo, fazia-se a apresentação e forneciam-se algumas informações sobre o manual e o programa. O profissional deve ser acolhedor, dar boas -vindas aos participantes do programa e cumprimentá-los pelo desejo de parar de fumar e buscar ajuda. A sessão objetivava "Entender por que se fuma e como isso afeta a saúde". Promoviam-se as apresentações individuais; formulava-se as quatro perguntas básicas: quanto você fuma? O que faz você fumar? Qual o obstáculo mais difícil para você deixar de fumar? Quanto tempo depois de levantar você acende seu primeiro cigarro? Faziam-se comentários após as respostas o mais individualizadamente possível. O objetivo dessa discussão era mostrar que a nicotina é considerada uma droga que causa dependência química, ou seja, a pessoa tem perda do controle sobre o uso da droga, em razão da necessidade psicológica e/ou física dela. A nicotina faz com que a pessoas fumem apesar de saberem dos sérios riscos à saúde. Isso explica porque grande parte dos fumantes deseja parar, mas não consegue. Pedia-se para pensarem no que os levava a fumar e nos hábitos tabagísticos no dia a dia como fumar 
após um cafezinho, após as refeições ou após acordar. Lembravase que o tabagismo causa prejuízos à saúde. Relacionava-se fumar cigarro Ás causas de vários tipos de doenças como: câncer, doença cardiovascular, doenças pulmonares crônicas e úlcera péptica, entre outras. Em seguida, era feito o aconselhamento sobre a importância de interromper o uso e sobre os riscos associados à saúde de uma forma clara, firme e individualizada. Reconhecia-se a ambivalência de muitos fumantes, que reconheciam que precisavam deixar de fumar, mas se mostravam divididos, pois desenvolviam prazer e relaxamento com o cigarro. Procurava-se enfatizar que o cigarro causava prazer com danos, e que é possível desenvolver outros prazeres sem esses danos, substituindo-se o cigarro por lazer, exercícios, técnicas de relaxamento, atividades manuais, atividades físicas, etc. Nessa sessão, determina-se a data de interrupção do uso e a proposta contratual de assistência. Explicava-se sobre os métodos para deixar de fumar. Definia-se parada abrupta como parar de fumar de uma hora para outra, cessando totalmente o uso do cigarro. Por outro lado, a parada gradual era aquela em que o fumante escolhia parar de fumar em alguns dias, por redução ou adiamento do primeiro cigarro da manhã.

A segunda sessão objetivava "Os primeiros dias sem fumar". Perguntava-se a cada participante qual a data que escolheu para deixar de fumar. Perguntava-se sobre o método desejado: parada abrupta ou gradual. Parabenizava-se os que já tinham parado e perguntava-se sobre suas experiências. Cumprimentava-se, também, os participantes que não pararam ainda, mas faziam esforço e tinham superado alguma situação difícil. Conduzia-se a reunião sobre a síndrome de abstinência e discutia-se como resistir à fissura. Informava-se que alguns fumantes apresentavam a síndrome de abstinência como dor de cabeça, tontura, irritabilidade, alteração do sono, mal-estar súbito (disforia) com sintomas ansiosos e, por vezes, uma ideia fixa de que aquilo só passará após o consumo. Explicava-se que esses sintomas duram de 1 a 3 semanas, e nem todo fumante os apresenta. Informava-se que a fissura era uma manifestação bastante comum, e que tendia a tornar-se cada vez mais esparsa, com o passar do tempo. Cada episódio não duraria mais do que 5 minutos, e depois desapareceria. Mostrava-se que 
existem estratégias para lidar com esses sintomas. Lembrava-se que a fissura era autolimitada. As maneiras de lidar com a fissura são por técnicas de relaxamento, assertividade e pensamento construtivo. Discutiam-se os sintomas de abstinência e a terapia de substituição com a nicotina.

A terceira sessão teve como área temática "Como vencer os obstáculos para permanecer sem fumar", analisando as melhorias e os benefícios físicos e mentais após parar de fumar e as situações de risco e de proteção. Eram discutidas com o objetivo de traçar estratégias de manutenção da abstinência.

Para os fumantes que sinalizavam o ganho de peso como uma barreira para deixar de fumar, informava-se sobre algumas técnicas de reeducação alimentar. Informava-se que a maior parte do aumento do peso ocorria em média nos primeiros seis meses após a cessação, estabilizando-se após 1 ano. Orientava-se sobre o esforço em prol de um estilo de vida saudável, abandonando o fumo, fazendo dieta. Recomendava-se que fosse aumentada a atividade física e fossem aprendidas técnicas de alimentação saudável. Para trabalhar o medo de não conseguir ou de recaída, mostrava-se que o paciente não estaria sozinho, e colocava-se à disposição para apoiálo. O apoio social era recomendado.

A quarta sessão objetivava "Benefícios obtidos após parar de fumar". Nessa fase, os pacientes definiam os benefícios a longo prazo e os fatores de risco de recaídas. Orientava-se sobre o uso de álcool como um desses fatores, no tabagismo. Após quatro sessões, os pacientes passavam por sessões de manutenção por um ano. Os que cessaram com o tabagismo eram estimulados a manteremse em abstinência, e os que não conseguiram eram encorajados a marcar a data para deixar de fumar, usando a mesma metodologia preconizada pelo Ministério da Saúde. (BRASIL, 1997).

Nas reuniões de manutenção, os pacientes foram orientados quanto à fase de acompanhamento por um período de um ano, para prevenção de recaída. Nessas reuniões, capacitava-se os pacientes a identificarem as situações de alto risco de recaída, e treinava-se habilidades comportamentais de enfrentamento que incluíam retirar-se das situações e substituições por outros 
comportamentos (estimulava-se a atividade física, despertava-se talentos, atividades manuais ou de grupo de apoio), utilizavam-se técnicas de assertividade e aumento da autoestima, relaxamento e dinâmica de grupo.

Manutenção de portas abertas foi um espaço criado para os pacientes que, a qualquer momento em que recaíssem, poderiam retornar ao grupo. Essas sessões são de estímulo e motivação para tentarem novamente deixar o tabaco. Nesse tipo de sessão, é realizado um recordatório das quatro sessões e selecionada alguma dinâmica ou técnica, de acordo com a necessidade do grupo.

Durante a fase de manutenção, é importante diferenciar lapso de recaída. Lapso é o uso isolado da droga, enquanto a recaída está relacionada à criação de um novo padrão de uso ou à volta ao padrão anterior. (PRESMAN, 2006).

As sessões temáticas da quinta à décima sexta intervenções terapêuticas foram elaboradas pelos profissionais de saúde do CRATT/ AHC/UEL.

Na quinta sessão, denominada "Balança decisória", os pacientes apresentam de um lado da balança as vantagens e desvantagens de fumar e do outro lado, as de não fumar. $\mathrm{O}$ recordatório visa verificar quais participantes cessaram o uso do tabaco e os que ainda não o fizeram, e quais suas modalidades de tratamento. Os objetivos dessa sessão podem ser representados por:

- $\quad$ reforçar os benefícios de quem parou o uso do tabaco;

- $\quad$ estimular os participantes que ainda não pararam;

- $\quad$ propiciar reflexão sobre os benefícios nas esferas psicossocial, familiar e ambiental da parada;

- $\quad$ identificar os custos da permanência com o tabagismo;

- trabalhar sentimento de ambivalência;

- ressaltar os benefícios e os custos a curto e longo prazo de se tomar a decisão, no caso, de decidir parar de fumar. 
Discute-se com os pacientes sobre que lado da balança pesa mais a motivação e a decisão de cessar o consumo do tabaco. A motivação é qualificada para mudanças a curto, médio e longo prazo, sumarizada no quadro 10.

\begin{tabular}{|l|l|l}
\hline PRAZO & BENEFÍCIOS DE MUDAR & CUSTOS DE NÃO MUDAR \\
\hline Em curto prazo & --------- & ---------- \\
\hline Em médio prazo & ----------- & ---------- \\
\hline Em longo prazo & & \\
\hline Vantagens & ------------- & --- \\
\hline Desvantagens & ----------- & ----------- \\
\hline
\end{tabular}

Quadro 10 - Balança decisória.

No encerramento da sessão realiza-se o resumo dela, orientando-se sobre as atividades de realização doméstica, que se trata do preenchimento do impresso da balança decisória em casa.

Na sexta sessão, denominada "Habilidades para lidar com situações de risco I", são listadas e discutidas as situações de risco e as barreiras para resistir ao uso do tabaco. Solicita-se a realização de um recordatório que visa verificar quais participantes cessaram o uso do tabaco e os que ainda não o fizeram, e quais suas modalidades de tratamento, assim como a melhor solução de enfrentamento, sumarizadas no quadro 11. 


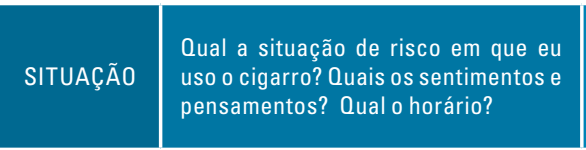

Qual a melhor solução para lidar com esta situação de risco?

Quadro 11 - Habilidades para lidar com situações de risco - Identificação e Soluções das Situações de Risco - I.

Os objetivos dessa sessão consistem em:

- identificar situações de risco vivenciadas pelos participantes;

- levantar estratégias adequadas para lidar com as situações de risco;

- oportunizar trocas de experiências entre os membros do grupo;

- apontar as situações comuns de recaída (solidão, consumo de álcool, stress, conflitos familiares, perdas, cobrança);

- participantes devem escolher frases ou figuras que representem situações de risco para eles próprios;

- discutir como essas situações podem ser resolvidas de forma assertiva.

Identificam-se as situações, os sentimentos, os pensamentos e os horários em que sentem fissura ou têm recaída para fumar, através de perguntas estimuladoras de discussão, como:

- $\quad$ Em quais momentos você mais sente vontade de fumar?

- $\quad$ O que fez para permanecer sem fumar?

- Quais as alternativas mais adequadas?

O resumo da sessão consiste em responder ao impresso da sessão em casa. 
Na sétima sessão, denominada "Manejo da Fissura e Relaxamento", o recordatório visa verificar quais participantes cessaram o uso do tabaco e os que ainda não o fizeram, e quais suas modalidades de tratamento. Os objetivos dessa sessão são:

- Relembrar sintomas da fissura, seus gatilhos e as alternativas para lidar com ela;

- Iniciar com exercícios de relaxamento (educação física ou a própria psiquiatria) como a Técnica de Schultz (autógeno), a Técnica de Jacobson (relaxamento progressivo) e a Técnica de visualização: olhos fechados, respiração abdominal, pensamentos ("Estou calmo, tranquilo, nada vai me perturbar...”, imaginar um lugar tranquilo como um riacho, uma praia, um campo), sentado ou deitado. Respiração lenta, abdominal, contração muscular progressiva e posterior com relaxamento simultâneo de todos os grupos musculares.

O resumo da sessão apresenta como tarefa:

- Fazer os exercícios de relaxamento em casa;

- Maneiras de lidar com a fissura:

- distração: prepare uma lista do que pode ser feito nessa hora (atividade física, arrumar o quarto, etc.);

- conversar com alguém sobre ela;

- eleger pessoas de fácil acesso e confiança, para telefonar;

- "entrar" na fissura;

- vivenciar as fases dela (pico súbito e descendente);

- lembrar as consequências negativas do consumo, que o levaram a buscar a abstinência;

- conversar consigo;

- fazer uma contraposição aos pensamentos que estimulam o consumo, nessa hora. 
Na oitava sessão denominada "Modificação do estilo de vida I", o recordatório constitui-se em verificar quais participantes cessaram o uso do tabaco e os que ainda não o fizeram, quais suas modalidades de tratamento e interrogar sobre a realização das tarefas da sessão anterior. Os objetivos dessa sessão constituem-se em:

- motivar o estilo de vida saudável (entrar em contato com a nutricionista);

- $\quad$ discutir alimentação saudável e exercício físico;

- $\quad$ perguntar ao grupo: o que é estilo de vida saudável? O que você já está fazendo pela sua saúde? O que você acha que ainda pode fazer para melhorar sua saúde? Quais as barreiras que o impedem de fazê-lo?;

- trabalhar sugestões com o grupo;

- trabalhar a motivação para atividade física: 30 minutos por dia (descer do ponto de ônibus antes do local desejado, andar com o cachorro, aulas de dança, etc.).

Para prevenir recaídas, é necessário motivar-se para uma mudança de estilo de vida saudável. Discute-se com os participantes acerca da importância das atividades físicas, da reeducação alimentar, da atividade de lazer, do manejo do stress e de buscar uma rede de apoio. Cada participante faz a sua proposta de vida saudável e suas ações para isso ocorrer. O resumo da sessão consiste na tarefa de listar que tipo de atividade física conseguiu-se fazer e trazer o diário alimentar de um dia.

Na nona sessão, denominada "Modificação do Estilo de Vida II", o recordatório constitui-se em verificar quais participantes cessaram o uso do tabaco e os que ainda não o fizeram, quais suas modalidades de tratamento e interrogar sobre a realização das tarefas da sessão anterior. Os objetivos dessa sessão constituem-se em: 
- $\quad$ motivar o estilo de vida saudável;

- corrigir o diário alimentar de um paciente como exemplo, os demais diários serão corrigidos e entregues posteriormente;

- discutir sobre o consumo de álcool, manejo de stress e situações sociais;

- trabalhar as consequências positivas (prazer) e negativas do consumo de álcool;

- falar sobre o manejo do stress e situações sociais - o que os participantes já conseguiram mudar e o que ainda pode ser melhorado.

Na reunião, discutem-se os objetivos da sessão a partir das experiências de cada participante. No encerramento da sessão, realiza-se o resumo dessa, orientando-se sobre a tarefa de relatar uma situação prazerosa, em que houve divertimento, sem envolver cigarro ou álcool.

Na décima sessão, denominada "Autoestima e assertividade I", o recordatório constitui-se em verificar quais participantes cessaram o uso do tabaco e os que ainda não o fizeram, quais suas modalidades de tratamento; e interrogar sobre a realização das tarefas da sessão anterior. Os objetivos dessa sessão constituem-se em:

- ajudar os participantes a entenderem os conceitos de passividade, agressividade e assertividade;

- trabalhar a importância da assertividade para a manutenção da abstinência do tabaco.

Na reunião, discute-se sobre a importância da autoestima e da assertividade (definida como a capacidade de expressar o que se pensa ou sente). Pessoas passivas não expressam o que pensam ou sentem, assim como pessoas agressivas, por outro lado, expressam seus pensamentos e sentimentos de uma maneira que visa controlar, 
dominar e/ou ferir outra pessoa. Para o alcance de uma discussão participativa, dividem-se os participantes em três grupos; cada grupo recebe uma história com uma situação cotidiana e como o personagem lidou com ela. Os grupos deverão discutir sobre a história e concluir qual a postura do personagem, se foi passiva, agressiva ou assertiva.

A meta, nessa fase, é ser assertivo, em vez de ser passivo ou agressivo, sumarizada no quadro 12 .

\begin{tabular}{l|l|l|}
$\begin{array}{l}\text { Pensamento } \\
\text { Negativo }\end{array}$ & $\begin{array}{l}\text { Pensamento } \\
\text { Positivo }\end{array}$ & Habilidades de Mudança \\
\cline { 3 - 3 } & $\begin{array}{l}\text { Quando tenho uma visão negativa de mim, o que posso fazer para } \\
\text { mudar? }\end{array}$ \\
\hline & Quais os passos que eu planejo mudar? \\
\hline & Como as pessoas podem me ajudar? \\
\hline Que coisas podem interferir nos meus planos? \\
\hline
\end{tabular}

Quadro 12 - Autoestima e assertividade - I

No encerramento da sessão, realiza-se o resumo, orientandose sobre a tarefa de relatar uma situação em que conseguiram ser assertivos.

Na décima primeira sessão, "Autoestima e assertividade II (solução de problemas)", o recordatório constitui-se em verificar quais participantes cessaram o uso do tabaco e os que ainda não o fizeram, quais suas modalidades de tratamento e interrogar sobre a realização das tarefas da sessão anterior. Os objetivos dessa sessão constituem-se em:

- trabalhar com os participantes a capacidade de resolver problemas.

Na reunião, discutir os relatos trazidos como tarefa da última sessão, escrever no quadro a situação e eliciar os participantes sobre 
qual seria a sua conduta; trabalhar com o grupo qual seria a melhor solução.

Nessa fase, utiliza-se de dramatizações para compreender e identificar a situação problema, bem como uma maneira de responder assertivamente as questões sumarizadas no quadro 13.

\section{IDENTIFICAR O PROBLEMA}

- Qual situação de risco que baixa minha autoestima?

- 0 que eu posso lembrar dos meus pontos positivos de sucesso?

- Como posso modificar meus pensamentos a respeito de mim mesmo?

- Quais situações que me levam à recaída?
SOLUÇÃO DE ASSERTIVIDADE

- Como posso resolver meus problemas usando a assertividade?

- Pense nas razões pelas quais não gostaria de voltar a fumar.

No encerramento da sessão, realiza-se o resumo, orientandose sobre a tarefa de responder: o que você entende por ansiedade? Trazer exemplos de situações que causem ansiedade.

Na décima segunda sessão, "Maneiras de lidar com a ansiedade", o recordatório constitui-se em verificar quais participantes cessaram o uso do tabaco e os que ainda não o fizeram, quais suas modalidades de tratamento e interrogar sobre a realização das tarefas da sessão anterior. Os objetivos dessa sessão constituem-se em:

- identificar as situações que geram ansiedade aos participantes;

- trabalhar com os participantes a capacidade de lidar com a ansiedade;

$\mathrm{Na}$ reunião, discutem-se os relatos trazidos como tarefa da última sessão, abordando sobre a ansiedade e seu manejo. Os 
participantes identificam quais as situações em que ficam ansiosos, as soluções e a escolha da melhor solução. Solicita-se que dramatizem uma situação em que havia risco de recaídas e a melhor solução para lidar com a ansiedade.

No encerramento da sessão, realiza-se o resumo, orientandose sobre a tarefa de responder :

- $\quad$ as mudanças que quero para as próximas semanas;

- $\quad$ as razões porque desejo mudar;

- $\quad$ os passos que planejo mudar;

- as maneiras como as pessoas podem me ajudar;

- $\quad$ as coisas que interferem nos meus planos.

Na décima terceira sessão, denominada "Modificação no estilo de vida III - Meu compromisso de mudança", o recordatório constitui-se em verificar quais participantes cessaram o uso do tabaco e os que ainda não o fizeram, quais suas modalidades de tratamento e interrogar sobre a realização das tarefas da sessão anterior. O objetivo dessa sessão é:

- identificar as situações de risco, as estratégias seguras e a motivação para mudança.

Na reunião, discutem-se os relatos trazidos como tarefa da última sessão, onde o paciente é motivado a planejar e administrar seu tempo de maneira adequada e como fazer sua agenda da semana. Os pacientes são motivados a buscarem atividades de prazer e lazer sem danos, através da identificação dos horários de risco e das recaídas podendo, assim, planejar uma alternativa saudável de lazer. Ressalta-se a capacidade individual para atingir seus objetivos pessoais e a promoção de sua saúde física e mental.

No encerramento da sessão, realiza-se o resumo, orientandose sobre a tarefa de responder um inventário de habilidades e 
estratégias de enfrentamento para lidar com as situações de risco, sumarizadas no quadro 14.

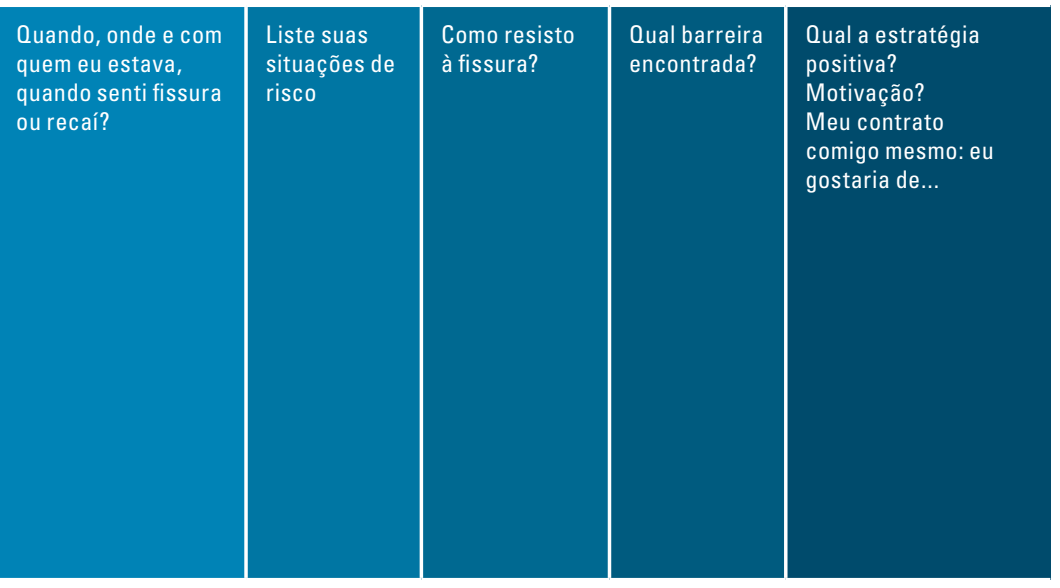

Quadro 14 - Estratégias de enfrentamento.

Na décima quarta sessão, "Habilidades para lidar com as situações de risco II", o recordatório constitui-se em verificar quais participantes cessaram o uso do tabaco e os que ainda não o fizeram, quais suas modalidades de tratamento e interrogar sobre a realização das tarefas da sessão anterior. O objetivo dessa sessão é:

- trabalhar com os participantes a capacidade de se desenvolver habilidades para lidar com situações de risco.

$\mathrm{Na}$ reunião, discutem-se os relatos trazidos como tarefa da última sessão. Nessa fase, procura-se identificar, evitar e manejar as situações de alto risco, e estudam-se as habilidades de que os pacientes dispõem e a forma mais segura para lidarem com cada uma dessas situações, sumarizadas no quadro 15. Busca-se desenvolver habilidades para lidar com situações de risco como: emoções negativas, situações difíceis, diversão e prazer, os condicionamentos, as pressões sociais, a fissura, os lapsos e recaídas. 


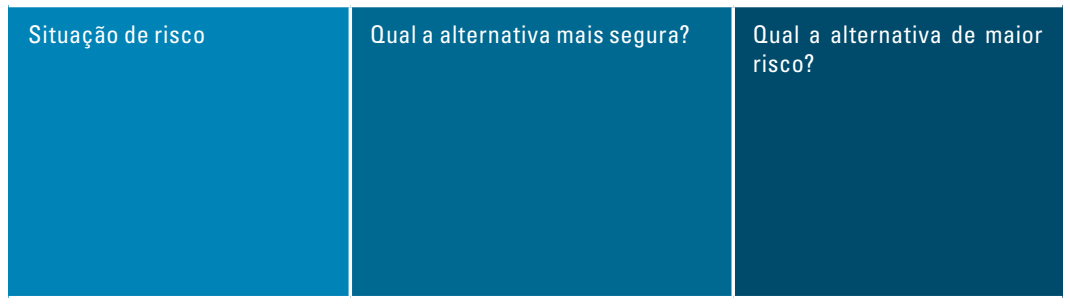

Quadro 15 - Habilidades para lidar com situações de risco - II - Alternativas seguras e de risco.

No encerramento da sessão realiza-se o resumo desta, orientando-se sobre a tarefa de listar um problema e explicar como o enfrentou.

Na décima quinta sessão, "Estratégias de enfrentamento", o recordatório constitui-se em verificar quais participantes cessaram o uso do tabaco e os que ainda não o fizeram, quais suas modalidades de tratamento e interrogar sobre a realização das tarefas da sessão anterior. O objetivo dessa sessão é:

- trabalhar com os participantes a capacidade de identificar situações problemas.

$\mathrm{Na}$ reunião, discutem-se os relatos trazidos como tarefa da última sessão e utiliza-se de dramatizações para compreender e identificar a situação problema, bem como uma maneira de responder assertivamente às questões sumarizadas no quadro 16.

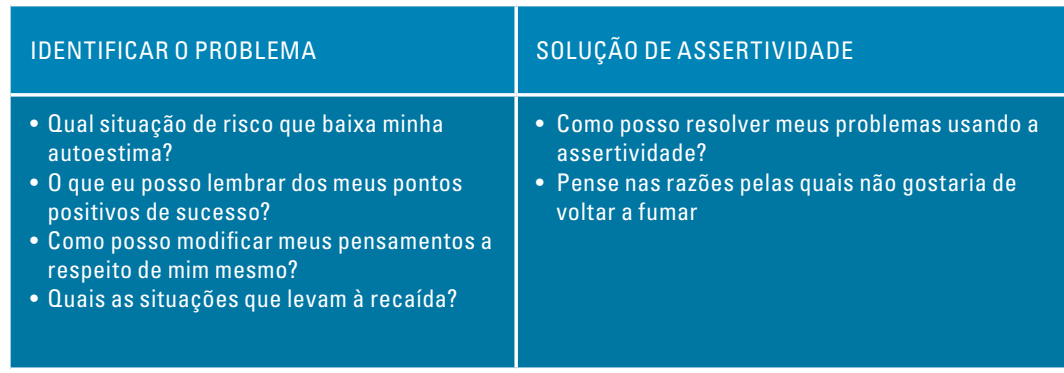

Quadro 16 - Estratégias de enfrentamento. 
No encerramento da sessão, realiza-se o resumo, orientandose sobre a tarefa de listar os benefícios adquiridos com a cessação do tabaco.

Na décima sexta sessão, "Encerramento", o recordatório constitui-se em trabalhar com os relatos da tarefa da sessão anterior. Nessa fase, há uma ênfase aos benefícios de cessar o tabaco, discutindo os aspectos positivos, negativos e as sugestões. Reforçam-se estratégias e soluções para lidar com as situações de risco, bem como buscar um grupo de autoajuda. Orienta-se, em casos de recaídas, para que não se sintam envergonhados em voltar para o programa, discutindo-se sobre o fato de que a recaída faz parte do tratamento, pois parar de fumar é um processo. A regra é: evite um cigarro e você evitará todos os outros. $\mathrm{O}$ encerramento está sumarizado no quadro 17.

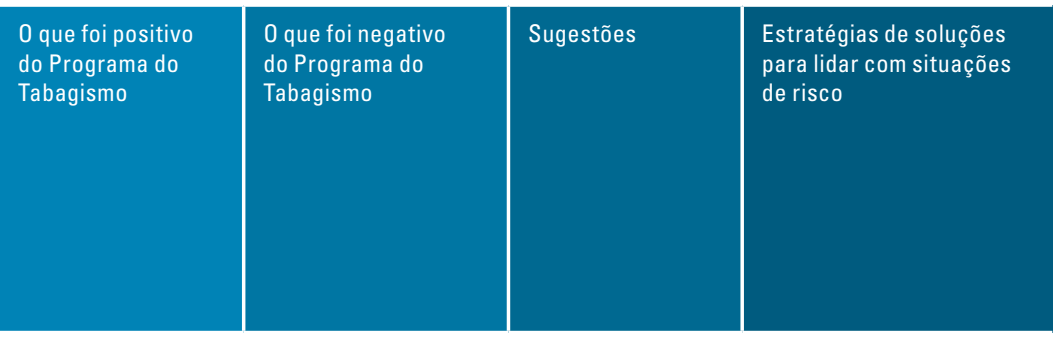

Quadro 17 - Encerramento.

O emprego do monóxido de carbono no ar exalado para a detecção de consumo de tabaco é realizado na avaliação e após cada sessão de tratamento, para verificar a sessão do tabagismo.

A mensuração do monóxido de carbono constitui um indicador de fácil emprego, baixo custo, não invasivo, e que fornece resultado imediato. Consiste na determinação da concentração de carbono no ar exalado. (SANTOS et al., 2001). 


\section{REFERÊNCIAS}

AMERICAN PSYCHIATRIC ASSOCIATION. Practice guideline for the treatment of patients with nicotine dependence. American Journal of Psychiatry, Arlington, v. 153, suppl. 10, p. 1-31, 1996.

. Diretrizes para o tratamento de Transtornos Psiquiátricos: Compêndio 2006. Porto Alegre: Artmed, 2008.

BRASIL. Ministério da Saúde. Secretaria Nacional de Assistência à saúde. Instituto Nacional de Câncer. Coordenação Nacional de Controle do Tabagismo e Prevenção Primária (Contapp). Deixando de fumar sem mistérios. Rio de Janeiro: INCA, 1997.

Ministério da Saúde. Instituto Nacional de Câncer. Abordagem e tratamento do fumante. Rio de Janeiro: INCA, 2001.

- Ministério da Saúde. Secretaria de Atenção à Saúde. Portaria SAS/MS 442/04 de 13 de agosto de 2004. Aprova o Plano de Implantação da Abordagem e Tratamento do Tabagismo no SUS. Brasília; 2004a.

. Ministério da Saúde. Instituto Nacional de Câncer. Coordenação de Prevenção e Vigilância. Deixando de Fumar sem Mistérios: Manual do Coordenador. 2.ed. Rio de Janeiro, 2004b.

MEIRELLES, R.; CAVALCANTE, T. Quais políticas de controle do tabagismo um país deve ter para chegar a um tratamento eficaz? A perspectiva governamental. In: GIGLIOTTI, A.; PRESMAN, S. (Org.). Atualização no tratamento do tabagismo. Rio de Janeiro: ABP-Saúde, 2006. p.171-189.

PRESMAN, S.; CARNEIRO, E.; GIGLIOTTI, A. Tratamentos nãofarmacológicos para o tabagismo. Revista de Psiquiatria Clínica, São Paulo, v.32, n.5, p.267-75, set./out. 2005.

. Intervenção Intensiva e Terapia de Grupo. In: GIGLIOTTI, A.; PRESMAN, S. (Org.). Atualização no tratamento do tabagismo. Rio de Janeiro: ABP-Saúde, 2006. p.27-51.

REICHERT, J. et al. Diretrizes da SBPT - Diretrizes para cessação do tabagismo - 2008. J Bras Pneumol, v.34, n.10, p.845-880, 2008.

SANTOS, U. et al. Emprego da determinação de monóxido de carbono no ar exalado para detecção do consumo de tabaco. Jornal de Pneumologia, v.27, n.5, p.231-6, set./out. 2001. 